\title{
Meeting the Need for Special Education Teacher Education: Universities Can Make It Difficult
}

\author{
An Australian Case \\ Philip J Doecke \\ RMIT University, Australia
}

\begin{abstract}
There are three initial teacher education programs for specialist teachers in the state of Victoria, Australia. As Australian Federal and State governments were starting to pay closer, more tangible attention to those with disability, one Australian university closed its Disability Studies single degree program, along with its associated Education/Disability program; this is a teacher education program. An examination of government data collection, reports, policy development and curriculum support activities sets out recent government directions with regards to special education in Victoria and Australia. Why then would a major program provider cut its program? In the examination of this case it is argued that an 'academic culture' may prevail within universities which see small specialist programs as unattractive to their overall purpose and appeal. Does this culture fit within the wider community view of support and need for specialist teachers for children with special learning needs? How well is this view understood? Can this understanding be improved?
\end{abstract}

\section{Introduction}

The case is presented of a disability studies and education (Education/Disability) teacher education program which was discontinued in an Australian university, during a period when Australian government decisions were addressing the needs of those with disability. The university decision to close a disability studies program just at that time appeared incongruous and remarkable. All university programs are accountable and face scrutiny. Special education teacher education programs also face close scrutiny by university administration. However, the 'academic culture' of a university and its leaders may impact its views of 'disability' and its related programs, with challenging outcomes.

The background to disability studies and special education in Australia is briefly discussed, with reference to new endeavours by the Federal and State governments and their Education departments to understand more about learners with disability, and how special education teacher education is placed in relation to these inquiries.

The closing of an education/disability teacher education program exemplifies how some in the academic community consider disability and special education. Decisions that were made within the university are reviewed and how these are perceived in light of government and national directions.

\section{Background}

Over the past five years there has been much political, social and media 'talk' about disability, social provision and support, across Australia [1]. Meeting the needs of learners with special educational needs has not had a strong past in this country, and so it is appropriate that this need is addressed with urgency and practical application.

There are three undergraduate programs in special education teacher education Victoria. The author's own experience in the field of special education teacher education is very new. He teaches and has undertaken previous research in the field of physical education, first as a teacher then as a teacher educator and researcher. In January 2011 he became program director for a double degree program which focused both on teacher education as well as support skills for those with disability: B Education/B Applied Science (Disability).

As a newcomer to the field first perceptions were made through engagement with the university's administration, current lecturers, feedback from students, and from others within the field. These perceptions suggested that there was a range of concerns, constraints, and challenges in the field of special education teacher education.

A review of literature, discussions and debate at association meetings, together with dialogue with experienced associates in the field revealed major concerns that, in reality, there has been a significant gap between political promises versus assurances of action for widespread support for children with special learning needs, families, schools, and 
teachers, and what is happening in most schools. A major report prepared and written by the Victorian Equal Opportunities and Human Rights Commission (VEOHRC), Held back: a report into the experiences of students with disabilities in Victorian schools highlighted a range of concerns regarding schools' capacity to provide successful learning and teaching experiences for children with disabilities in Victorian schools, with positive outcomes for learners.

\begin{abstract}
When students with disabilities are unable to enjoy a good education, their future is seriously compromised. A poor education is one of the key reasons why the economic and social participation rate of Australians with disabilities is so low [2].
\end{abstract}

The report stated that existing Disability Standards for Education 2005 [3] and the Students with Disabilities Guidelines [4] were not being widely met in schools across Victoria, despite being mandated for implementation in all schools.

In response, in part to this report, more recently there is a slowly increasing range of reviews, reports, data collection and official policy directions under way, where the needs of children with special learning needs, families, schools and teachers are being identified and discussed.

The most recent of these in Victoria is the Special Needs Plan for Victorian Schools which was launched by the Victorian State Minister for Education in November 2014 [5].

The new Australian Curriculum (currently being rolled out) makes recommendations for Disability and Inclusion, how to develop, incorporate and implement appropriate curricular and contextual modifications to meet learners' needs. The Australian Curriculum, Assessment and Reporting Authority (ACARA) recognises the need to meet the learning requirements of students with disability, and continues to consult with representatives to work towards producing a diverse and successful curriculum for learners with special learning needs [6].

A leading consultative body is the Australian Association of Special Education (AASE) - the key professional association for special education in this country. It has provided recommendations and guidelines for pre-service teacher training particularly through its Position Paper of March, 2004. Currently in 2015 it is reviewing and updating this Position Paper in response to the Australian Federal Government's Teacher Education Ministerial Advisory Group's (TEMAG) report Students First.
In this report a short reference is made to the need for required courses to be provided for pre service teachers to meet the needs of learners with disability [6]. Beginning teachers were described as being inadequately equipped to address diverse student learning needs. The Victorian Labor Government's Special Needs Plan for Victorian Schools sets out the condition for teacher registration that all new teachers will be required to have completed a special needs component as part of their tertiary studies. The TEMAG report recommends that in order to work effectively with special needs students, and "in particular students with disability and learning difficulties, [pre-service courses] ought to be considered a core requirement of all teachers rather than a specialisation" [24].

The Australian Professional Standards for Teachers (produced by the Australian Institute for Teaching and School Leadership, AITSL) sets out the professional standards expected of teachers nationwide. The Focus area 1.6 Strategies to support full participation of students with disability states that graduate teachers ought to "demonstrate broad knowledge and understanding of legislative requirements and teaching strategies that support participation and learning of students with disability" [7].

However, beyond those stated above, the acknowledgement of the role of special education initial teacher education and postgraduate teacher education programs is barely mentioned elsewhere: for the successful equipping of teacher education graduates in having understanding and skills of development, incorporation and implementation of appropriate curricular, contextual and behavioural modifications to meet learners' needs.

The Australian Government is collecting data on school students with disability. This ongoing data collection process is known as the Nationally Consistent Collection of Data on School Students with Disability, and up to one-third of all Australian schools participated in the Data Collection for its first data release scheduled for 2015 [8]. It aims to provide information based upon these data to enable Australian schools to better determine levels of adjustment that are provided to assist students' learning, and accessing schools' facilities and resources. This data will further inform government leaders on students with a disability in schools, and enable decisions to be made to support schools and children with disability in their learning [9].

The concept of 'inclusion' has been widely discussed, and has a high priority in education including in Australian and Victorian policy and guidelines [10], [11]. This principle is a requirement to be embedded in all teacher education courses and 
programs. However, the extent of effectiveness and capacity of new teachers to meet the needs of children with disability in their classrooms is not being well addressed in reality [2]. Much of the difficulty of achieving successful and complete inclusion occurs through shortcomings in the teacher education programs.

In addressing the needs of all children in Victoria schools, those with disability and those without disability, the VEOHRC reports that

inclusive schools require a teacher
workforce that is properly equipped to
meet the learning needs of all students in
their classrooms. Over half of the
educators surveyed said they did not have
the support, training and resources they
needed to teach students with disabilities
well. To achieve this, pre-service training
at university and ongoing professional
development programs require a stronger
focus on understanding and teaching
students with disabilities, across the full
range of disabilities [2].

Few additional supporting references can be found which reflect this concern. It's almost as if it were assumed that it was happening.

\section{Constraints to a special education teacher education program}

The case is presented of a special education teacher education program in Australia which experienced constraints, even the threat of closure. The events that took place at a university and its double degree Education/Disability program are set out here. Contributing issues, understandings and values that may have impacted decisions made in these events are discussed.

The core undergraduate course in the Disability Studies discipline at this Australian university had been a three year undergraduate degree program (B Applied Science (Disability Studies) offered in the School of Health Sciences for over 25 years.

In 2006-7 the heads of the Schools of Health Sciences and Education proposed the development and offering of a 4-year double degree: B Education/B Applied Science (Disability), with half the courses provided by each School. It was 'owned' by the School of Education, and took its first enrolment in 2008.

Upon graduating the first cohort in 2011 the majority of this group were employed in mainstream primary schools, with around twenty percent being employed in special schools, and five percent in government support departments for families of those with disability. In following years the balance for graduates has shifted notably towards the majority seeking and being employment in special schools, with around five percent still being employed in government or support agencies and organisations.

The author became its second program director in January 2011.

In August 2011 two significant announcements were made regarding disability in Australia. The then Australian Prime Minister (the Hon. Julia Gillard) announced the National Disability Insurance Scheme (NDIS, and is now known as DisabilityCare Australia), a nation-wide program to be funded by the Federal Government to better identify and provide support to individuals, carers, and families of those with disabilities [12].

The same week the Head of the School of Health Sciences announced the closure of Disability Studies in Health Sciences. By closing Disability Studies in Health Sciences it automatically closed the double degree program in the School of Education.

There was immediate significant national, state and local feedback, asking, with concern, for reasons why [13] [14].

The university formed a Working Party 2012 to develop a response to this question, and to determine any possible future for Disability Studies at this university. The response, presented in the Disability Education at __ Review Working Party Report [15], defended its decision on the basis of "declining demand for entry into the program and low academic scores of entrants, which in turn were impacting on the financial viability of the program".

At this early stage of proceedings the School of Education wondered if any thought was given to the principal purpose of the double degree, namely, teacher education? [16]. No data was presented in the Working Party Report which reflected any declining interest for applicants to enter and study to graduate as a teacher qualified with the double degree, with its specialist education skills in teaching learners with special learning needs. On the contrary, the findings of the Review Working Party identified that "in Australia, the demand for teachers to work in neighbourhood and special schools is high and growing, with the consistent finding that insufficient special education teachers are available to meet the present and likely future demand" [15].

Therefore, the decision to close Disability Studies in the School of Health Sciences appeared to be made purely on the basis of academic recognition only within the School of Health Sciences, overlooking the position of the School of Education, 
or being reluctant to consider the viable and proven position of the Education/Disability program within the School of Education. No record of discussion by the Working Party members can be found relating to the double degree and the School of Education's success with its first few years of running this program [15].

Pursuant to this decision and its consequence, then, the question was posed: Was there a need for graduates to teach in mainstream and special schools with specialist studies in disability studies?

Over the next eighteen months inquiries were undertaken by the program director across the state of Victoria as to the need for graduates of the B Education/B Applied Science (Disability) program.

Around twenty metropolitan and country schools were visited as part of this inquiry. The Principals Association of Special Schools (PASS) was addressed. Advocacy group meetings (STAR Victoria Education Alliance) were attended, where they were briefed as to what had happened to the Education/Disability program, and its likely impact upon the provision of specialist graduate teachers. A meeting was held with the executive director of Children with Disability Australia.

Examples of responses provided by school principals and assistant principals during these inquiries were:

"I need seventeen of your graduates next year." (Campus principal of a School for Autism).

"I've just employed four of your graduates this year, and I'll need four more next year." (Assistant principal for a special developmental school within the university's region).

A notable concern was expressed while visiting country town schools. Many schools were fortunate if at least their principal had special education teaching qualifications; few other teaching staff did. Several principals and assistant principals expressed a strong desire to employ graduates with special education qualifications, if they would apply.

Having 'lost' the Disability Studies single degree, the double degree could no longer exist in its current format according to university policy, where two existing host degrees needed to be available to contribute courses to the double degree.

Following the inquiries made to schools in Victoria, a range of recommendations was formulated. These had the intention of retaining a special education presence in the teacher education programs offered by the School of Education. Based upon these recommendations:
The courses taught by the School of Health Sciences were wholly transferred to the School of Education.

The learning-teaching focus would be adjusted to children and young people of school age: birth to 18 years. The double degree had taken a lifespan approach. By moving the double degree into the School of Education the Disability Studies component lost learning to provide services for adults with disabilities.

It would be rewritten as an undergraduate B Education specialisation (major).

Provision was made for those currently enrolled in the Education/Disability double degree program to complete the program for which they had been accepted and enrolled by the university. This final cohort will graduate in December 2016.

The new specialisation degree was developed over 2012 and 2013, and approved for offering by the School of Education as a specialist initial teaching degree in February 2014 by the state's teaching accrediting authority (Victorian Institute for Teaching, VIT). Eight specialist education courses are embedded within the second, third and fourth years.

The courses are:

- Education Settings and Society

- Introduction to Education and Disability

- Teaching Children with Disabilities Communication

- Teaching Children with Disabilities Teaching Strategies

- Positive Behaviour Support in Education

- Inclusive Education

- Working with Disability Support Networks

- Teaching Children with Complex Needs.

Experienced, well qualified specialist teachers have and are being identified to finalise these courses for quality, well-resourced teaching.

Its initial intake commenced in February 2014 with twenty-four students. In its second year thirty students accepted the offer of a place.

A key strength for each course is the number of hours students spend working alongside teachers in special school classrooms (Work Integrated Learning, WIL, is a central focus of the university's teaching-industry alignment).

\section{Discussion}

There are very many points that could be made from this case. A few have been selected for brief consideration here. 


\subsection{Culture}

A prevailing academic culture arguably may have impacted decisions made in this case. Responses from the university's leading academics involved in this process were mixed. Leadership in the School of Education expressed great disappointment [16].

Most Australian universities are directed by a culture which sees financial success a key motivating factor for institutional sustainability, vigour and viability. The reciprocal impact of financial success is academic strength, driven by research and industry contributions, commitments and partnerships. If a program does not attract external funding, it may be perceived by the university's leadership to be a less attractive element of the university, which aims to maintain a strong financial, research and industrial status. And during that time (2011 - 2014), Federal Government funding was under financial cutbacks [17] [18]. All programs are under scrutiny as to academic attractiveness and viability. If small, and not seen to be attracting academic attention through research outputs or external funding, it's not a popular program.

A university leader may be held in very high regard due to their high academic, global profile. Such a profile can carry significant power in the academic culture. The head of school evaluated the programs offered, and quickly assumed the position that the Disability Studies program was low in enrolment potential. The opinion that this program was weak was a compelling argument and led to a decision to close the program; this was accepted quickly, and apparently with little debate [15]. The academic power of that leader was a characteristic which saw senior university administrators accept that recommendation with minimal argument or without attempted rebuttal. Other university leaders such as that of Education expressed disappointment [16]. That the decision was made quickly prompted one commentator's opinion was that it was taken with "indecent haste" [19].

Prior to presenting this paper to a World Congress on Special Needs Education-2015, and subsequent development of this article, the writer discussed these events at length with the program heads of other special education teacher education programs in the state of Victoria. Their programs are also under close scrutiny. The provider of possibly the largest special education program in Victoria has now had its permanent teaching staff numbers reduced from four to one [20]. This is of concern when the need for trained special education teachers is very great and ought arguably to be expanding, when in effect specialist teacher education programs are at risk of closure or reduced support.

\subsection{Socio-cultural and community attitudes and responses}

Individuals in some communities in Australia have beliefs that include viewing 'disability' as a result of divine rejection or bad luck [21]. Australia is populated with folk from very many cultures from across the globe. Discussions with principals of schools within communities which have a high proportion of a particular nationality living in suburbs around their school have described understandings shared by folk of that culture about disability. These community members very often bring beliefs and understandings of disability which have been held for generations. Despite now living in Australia which is endeavouring to grow positively in its response to those with disability through understanding, respect, support and inclusion, many cultural views of disability still influence sociocultural groups. Some of these see disability in a negative light. This is a large and provocative topic, which is the focus of further research.

"Let's face it Phil. Disability's not sexy" [22]. This was the comment made by a highly respected special school principal during a PASS meeting. This statement indicates how principals of the eighty schools which are members of PASS Victoria often experience community feelings and sentiments concerning the children in their care and undertaking learning activities in their schools. This is a powerful statement when it reflects on community values and acceptance of a section of the neighbourhood and local community. There is a perception about those with disability not being attractive. Therefore there are also those who would not feel comfortable associating with those with disability. It could be argued that there are those within the university culture who might not find disability studies attractive, or of worth to retain in the university suite of programs.

Within the national political sphere decisions have to be made about the distribution of public money raised from taxpayers and similar revenue sources. Funding projects which positively influence the majority of the voting population is desirable for political sustainability. The decision made in 2011 by the Gillard Labor Government to establish a major funding commitment to support those with disability and their carers was significant, and how that government legislated to secure the promised funds has been under examination because it again is geared to meet the needs of a minority group - those with disability. Governments don't generate revenue 
from the disability sector - it's a costly sector to provide for and equip. Governments are required to provide specialist schooling and teachers. It responds to community applications to provide specialist facilities - but again, many scrutinise 'charitable' expenses, again asking if is cost-effective and necessary? Sadly the provision of facilities for those with disability is often perceived as charity. How will universities therefore consider special education teacher education programs?

Numbers of students willing to enrol in specialist teacher education programs are not large. Is it cost effective for a university to offer these programs?

The current Head of Education is supporting recommendations for the new developing program specialisation as, among other evidence, the need for skilled special education teachers is stated by principals of schools in the region around the university with whom partnerships have been developed. These are mainly mainstream schools, not just special schools.

\section{Recommendations}

Recommendations are posed whereby special education teacher education can be better addressed, and whereby an enhanced attitude can prevail. They may serve as a checklist of activities whereby leaders in the special education teacher education can take a greater responsibility towards the growth and effectiveness within the field. The School of Education, within the university, needs to be encouraged to find motivation from the schools and community with whom it has developed partnerships, to look for and find ways for resurgence of its teacher education programs to meet the significant needs for specialist teaching graduates for schools across the state.

1. Program accountability: as it's a small program it doesn't attract revenue for the university's coffers, therefore the School needs to ensure it has academic strength, integrity and validity. In return, academic staff should be research active, developing a profile which may interest fellow academics and even external financial providers. Research activities should be undertaken in special education teacher education issues to report to the academic community. Academic and teaching staff should be encouraged to develop the foundations of their own and others' teaching experience to provide the best possible course content and learning experiences.

2. Successful models from overseas should be examined; what worked well for them? Academic and teaching staff should develop communication with and learning about the experiences of those from other countries.

3. Explore the capacity and willingness to take action. Be involved in the wider community: this is the best way to address apathy or misconceptions. University personnel should represent the program in advocacy groups such as Children with Disabilities Australia.

4. Dialogue needs to be developed with the broader community, especially where cultural views of disability may perceive it as a negative trait, to present constructive outcomes and capacity to contribute by those with disability who are part of their own families and community.

5. Communication and promotion: the School needs to advertise and sell its program offering to potential students. The history of low interest by potential applicants to the program as potential specialist pre-service teachers needs to be addressed; Education Support personnel currently serving in schools ought to be advised as to their high suitability to upgrade to special education teacher education programs.

6. Partnerships: These should be strengthened with schools from around the region. This has already started with not only pre-service teachers being placed on practicum (WIL) in regional schools, but also leading teachers from the schools are helping developing and build new courses for delivery in the new specialist program.

7. Responsible monitoring and management: All aspects of the new program should be measured against national teacher education standards. Specialist teacher education standards are being proposed for consideration and possible implementation in Australia.

8. Collaboration: The program leaders of the four face-to-face programs of four Victorian universities plan to meet to initiate and develop dialogue and collaboration. It is inappropriate to compete when the need to graduate skilled specialist teachers is so great, and widespread.

\section{Conclusion}

Education authorities within Australian Federal and State Governments are deepening their understanding of, and developing policies and strategies towards meeting, the needs of students with disabilities. While this will take time and is not yet widespread it is noteworthy that there is increasing awareness of the importance of strengthening the position of teacher education in special educational needs. However the university culture has shown diverse and sometimes indifferent attitudes and responses to this movement. The case 
has been presented of a university with a long-lasting Disability Studies program and associated Education/Disability program that was quickly closed by an opinion posed by a senior academic. On this one occasion the approach was unhelpful to the community, and was a cause of concern to many in the university and the community, including the Federal Government and its Minister for Disability Reform, Macklin.

In response to this decision those in the School of Education undertook to redevelop the program to meet the need for special education teacher graduates. Strong evidence was found through engagement with and visits to schools that the need for specialist teachers in schools has in no way abated, rather, is growing and will be needed for many years into the future before schools' special education teaching needs are met. The teacher education double degree program ought not to have been closed. However, the re-development of the specialist program has seen its replacement as a strong new offering.

Were there other unacknowledged issues, preconceptions, notions, by the one or few who made the initial recommendation to discontinue the program? Further, does an 'academic culture' understand the difficult-to-define human characteristics of 'empathy' and 'care'? These are criteria which arguably have been overlooked in the unfolding of this case. Do these have any place in decisions pertaining to the retention or closing of small university programs? In selection criteria for recruiting potential students, how does one put a measure on the 'compassion' that they may or may not display?

'Academic culture' is a contentious issue with many opinions that can contribute to the debate. Further, there continues to be differing views of disability. However, those responsible for the teacher education programs in the School of Education of each university can take positive steps towards meeting the need for skilled graduate teachers by engaging with the community and its schools through dialogue and discussion, inviting them to participate in working with the schools, embodying community values into a positive and constructive curriculum. Academic lecturers and teachers need to undertake research to engage with their specialisation, to enrich and support their work.

"For years people with disabilities have been excluded, forgotten and ignored. Now they demand to have their voices heard" [1]. Teacher education programs in Australian universities can be encouraged and persuaded that the specialist teacher education programs they offer they are central, that they are the small steps taken which can make a leap of difference to an increasingly recognised group in the Australian population. Special education teacher education needs to be supported to take this crucial step in this country - and contribute their voice for the best possible experiences to meet the special learning needs of children with disabilities in our schools.

\section{References}

[1] National People with Disabilities and Carer Council. (2009). Shut Out: The Experience of People with Disabilities and their Families in Australia. National Disability Strategy Consultation Report. Commonwealth of Australia.

[2] Victorian Equal Opportunities and Human Rights Commission (2012). Held back; the experiences of students with disability in Victorian schools. VEOHRC.

[3] Department of Education and Training. (2006). Disability Standards for Education 2005. Commonwealth of Australia.

[4] Victorian Curriculum and Assessment Authority. (2005). Students with Disabilities Guidelines. Victorian Essential Learning Standards. VCAA.

[5] Department of Education and Training. (2014). Special Needs Plan for Victorian Schools. DET.

[6] Australian Council for Assessment, Curriculum and Research (2014).

(www.australiancurriculum.edu.au/studentdiversity/student s-with-disability (30 September, 2015).

[7] Australian Institute for Teaching and School Leadership. (2012). Australian Professional Standards for Teachers. AITSL.

[8] Blackwood, A. (2013). Nationally Consistent Collection of Data on School Students with Disability. Children with Disability Australia. Emailed correspondence.

[9] Standing Council on School Education and Early Childhood (2013). Nationally Consistent Collection of Data of School Students with Disability. DEECD.

[10] Hyde, M., Carpenter, L. \& Conroy, R. (eds.). (2014). Diversity, Inclusion \& Engagement. Oxford University Press, South Melbourne.

[11] Foreman, P. \& Arthur-Kelly, M. (2014). Inclusion in Action (4th ed.). Cengage, South Melbourne.

[12] Young, S. (2011). Ready for a National Disability Insurance Scheme. Ramp Up, ABC. www.abc.net.au (September 30, 2015). 
[13] Whitson, R. (2011). Free labour vanishes after uni course cut. Northern Weekly.

[14] Sobb, M. (2011). Why RMIT should keep disability degrees. ABC Ramp Up. www.abc.net.au (September 30, 2015).

[15] Working Party. (2012). Disability Education at RMIT Review Working Party. Unpublished report.

[16] Gough, A. (2011). Emailed departmental correspondence.

[17] ABC News. (2013). Educators, MPs furious over university funding cuts. (September 30, 2015).

[18] Holderhead, S. (2014). Cuts to university funding means cost of degrees to skyrocket. www.adelaidenow.com.au/news/south-australia.cuts-touniversity-funding-means-cost-of-degrees-to-skyrocket. (October 19, 2015).

[19] Hawley, S. (2013). www.abc.net/news/2013-0413/gonski/4627278. (October 19, 2015).

[20] Keeffe, M. (2015). Personal communication.

[21] Chen, C. (2014). Personal communication.

[22] Mooney, J. (2012). Personal communication.

[23] Merlino, J. (2014). Labor's Special Needs Plan for Victorian Schools. State Government of Victoria. Press release.

[24] Teacher Education Ministerial Advisory Group. (2014). Action Now: Classroom Ready Teachers. Department of Education and Training.

[25] Walkley, J. (2013). Emailed departmental correspondence. 